\title{
Impacts of the Load Models on Optimal Planning of Distributed Generation in Distribution System
}

\author{
Aashish Kumar Bohre, Ganga Agnihotri, Manisha Dubey, and Shilpa Kalambe \\ Electrical Engineering Department, Maulana Azad National Institute of Technology (MANIT), Bhopal 462003, India \\ Correspondence should be addressed to Aashish Kumar Bohre; aashu371984@gmail.com
}

Received 21 May 2015; Revised 4 September 2015; Accepted 8 September 2015

Academic Editor: Alaa Sheta

Copyright ( 2015 Aashish Kumar Bohre et al. This is an open access article distributed under the Creative Commons Attribution License, which permits unrestricted use, distribution, and reproduction in any medium, provided the original work is properly cited.

\begin{abstract}
The optimal planning (sizing and siting) of the distributed generations (DGs) by using butterfly-PSO/BF-PSO technique to investigate the impacts of load models is presented in this work. The validity of the evaluated results is confirmed by comparing with well-known Genetic Algorithm (GA) and standard or conventional particle swarm optimization (PSO). To exhibit its compatibility in terms of load management, an impact of different load models on the size and location of DG has also been presented in this work. The fitness evolution function explored is the multiobjective function (FMO), which is based on the three significant indexes such as active power loss, reactive power loss, and voltage deviation index. The optimal solution is obtained by minimizing the multiobjective fitness function using BF-PSO, GA, and PSO technique. The comparison of the different optimization techniques is given for the different types of load models such as constant, industrial, residential, and commercial load models. The results clearly show that the BF-PSO technique presents the superior solution in terms of compatibility as well as computation time and efforts both. The algorithm has been carried out with 15-bus radial and 30-bus mesh system.
\end{abstract}

\section{Introduction}

The practical system comprises various kinds of loads. Many researchers have explored efficient siting and sizing methods for distribution system. However, most of them have assumed constant load models. Constant load shows insensitivity to variations of frequency as well as voltage profile of the system. This depicts the ideal situation of the system. Thus all those methods fail to present the practically sound solution. It is observed that actual practical system comprised industrial, residential, and commercial loads. The Genetic Algorithm (GA) is genetic based evolutionary search algorithm. The basic concepts and applications of the Genetic Algorithms (GAs) including the various fields of optimizing the complex problems in a practical way for different functions have been analyzed in [1-3]. The standard or conventional particle swarm optimization (PSO) based optimization approach is given in [4-6]. The butterfly-particle swarm optimization (butterfly-PSO or BF-PSO) technique is based on the characteristic, behavior, and intelligence of the butterfly swarm search process for food, hence attraction towards food (or nectar) source which is described in $[7,8]$. The simple and efficient method for solving load flow case radial distribution networks proposed by [9] involves only the evaluation of a simple algebraic expression of voltage magnitudes. The multiobjective function is based on system performance indices to determine the location and size of distributed generation with the load models in the distribution system by $[10,11]$. The new concept for the network reconfiguration problem considering the distributed generation (DG) to minimize the real power loss and voltage profile improvement of the distribution system is reported in [12]. The analysis of several performance indexes for multiobjective function approach in distribution network with different power factor (PF) of DG and also considering the wide range of technical issues for distribution system are presented by [13]. The different power flow methodologies to solve load flow problems are described in [14-16]. The DG planning for mesh system with several techniques is reported in $[17,18]$.

This paper presents the optimal sizing and siting of distributed generation (DG) with the different type of load models. Then DG is considered as an active power source 


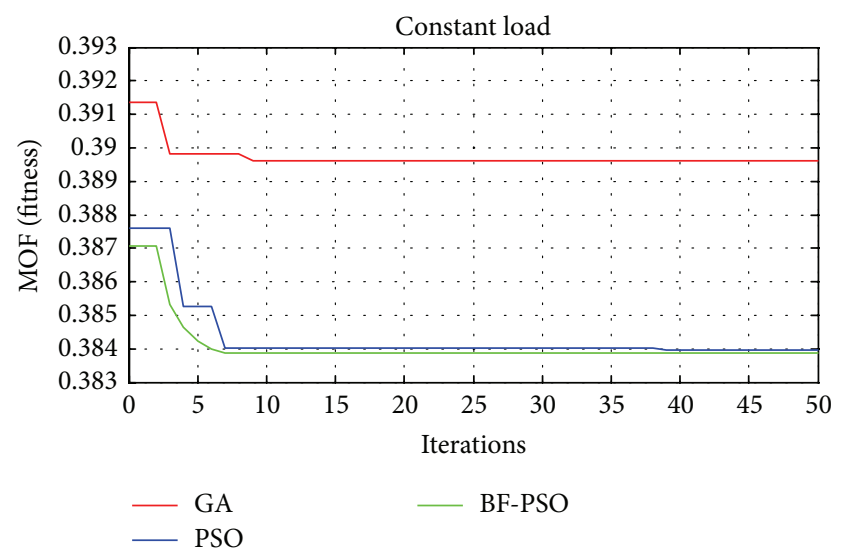

(a)

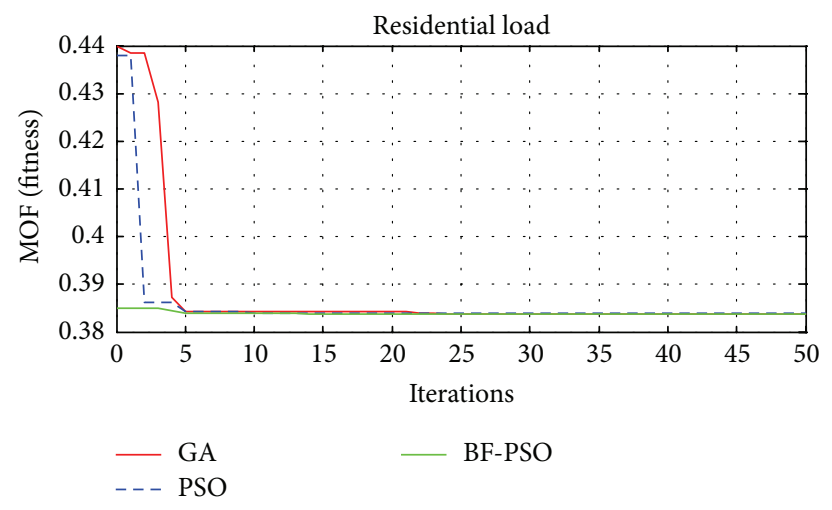

(c)

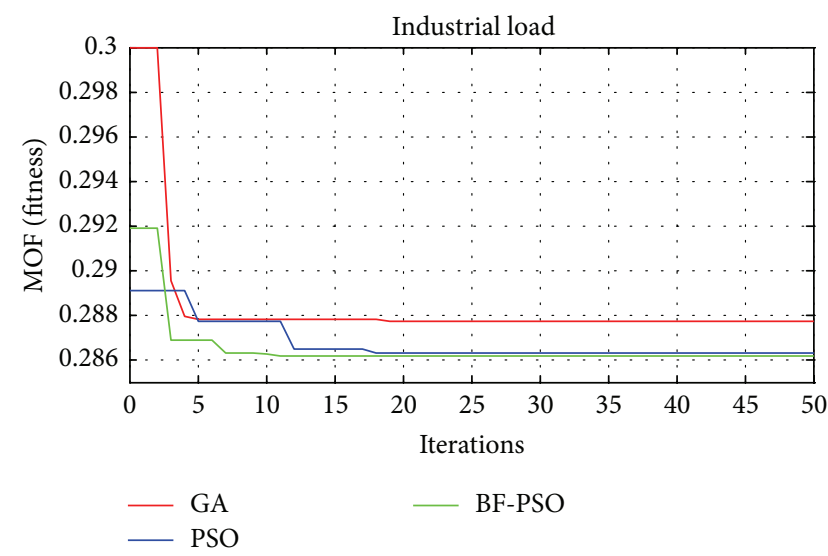

(b)

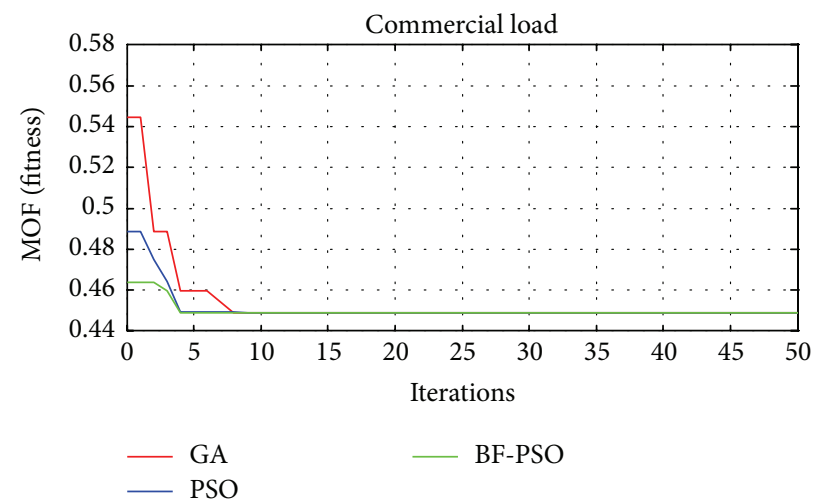

(d)

FIGURE 1: The convergence of multiobjective function (FMO) with iterations of 15-bus radial system for (a) constant load, (b) industrial load, (c) residential load, and (d) commercial load.

at load bus. The optimal site allocation and sizing of DG with the different objective indices such as active power loss index (PLI), reactive power loss index (QLI), and voltage deviation index (VDI) based multiobjective function have been evaluated as fitness function. The presented results exhibit the impacts of the different load models on the overall performance of the distributed system. The evaluated results show that the BF-PSO leads GA and PSO in terms of computational time and efforts. In spite of that, the better performance characteristics can be obtained by using BF-PSO.

\section{Problem Formulation and Load Models}

To find the optimal sizing and siting of the distributed generation (DG) in the radial system with the various objectives is achieved by the accompanying multiobjective function (FMO) as

$$
\mathrm{FMO}=k_{1} \times \mathrm{PLI}+k_{2} \times \mathrm{QLI}+k_{3} \times \mathrm{VDI}
$$

where $\sum_{i=1}^{3} k_{i}=1$ and $k_{i}$ is the weight factor for the different index. The values of $k_{1}, k_{2}$, and $k_{3}$ are $0.45,0.25$, and 0.3 , respectively. The details to select the weight factor of the indices are given in $[11,12,14]$.
The active power loss index (PLI) is

$$
\mathrm{PLI}=\frac{\mathrm{PL}_{\mathrm{DG}}}{\mathrm{PL}_{\mathrm{No}-\mathrm{DG}}} .
$$

The reactive power loss index $(\mathrm{QLI})$ is

$$
\mathrm{QLI}=\frac{\mathrm{QL}_{\mathrm{DG}}}{\mathrm{QL}_{\mathrm{No}-\mathrm{DG}}} .
$$

The voltage deviation index (VDI) is

$$
\mathrm{VDI}=\max _{j=2}^{n}\left(\frac{V_{\text {reff }}-V_{\mathrm{DG} j}}{V_{\text {reff }}}\right),
$$

where $\mathrm{PL}_{\mathrm{DG}}$ and $\mathrm{PL}_{\mathrm{No}-\mathrm{DG}}$ are real power loss with and without DG. The $\mathrm{QL}_{\mathrm{DG}}$ and $\mathrm{QL}_{\mathrm{No}-\mathrm{DG}}$ are reactive power loss with and without DG. The $V_{\text {reff }}$ and $V_{\mathrm{DG} j}$ are the reference or rated voltage and with-DG case voltage at bus $j$.

The load models for the particular loads can be mathematically expressed as

$$
\begin{gathered}
P_{i}=P_{o i} V_{i}^{a}, \\
Q_{i}=Q_{o i} V_{i}^{r},
\end{gathered}
$$




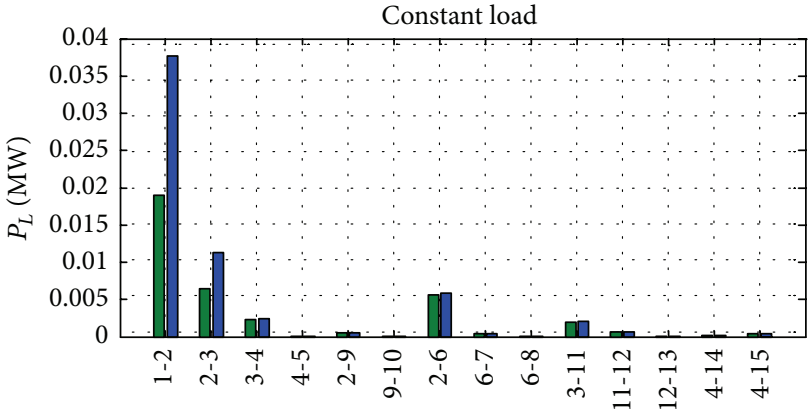

Branch number

No-DG

DG-BFPSO

(a)

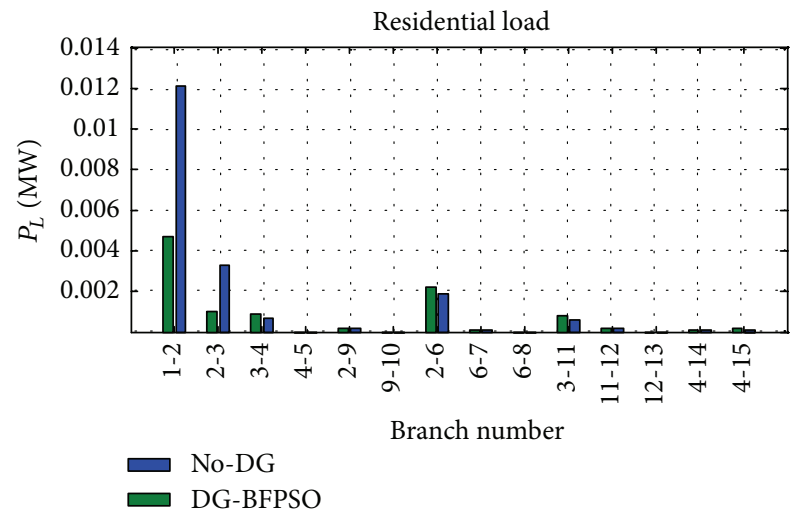

(c)

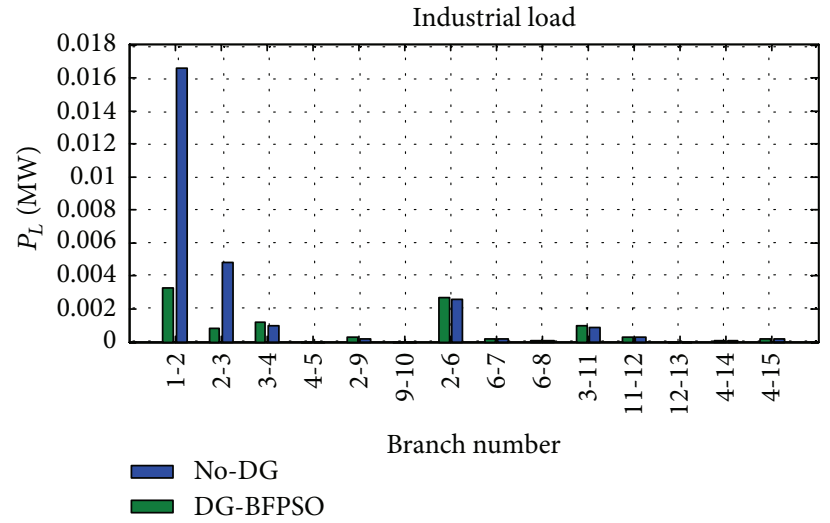

(b)

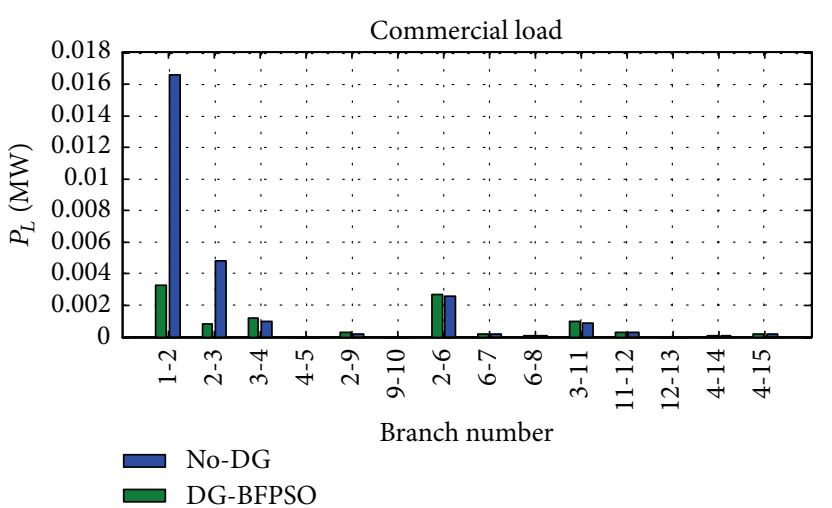

(d)

Figure 2: Active power loss of 15-bus radial system for (a) constant load, (b) industrial load, (c) residential load, and (d) commercial load.

TABLE 1: The exponent values for load models.

\begin{tabular}{lcc}
\hline Load type & $a$ & $r$ \\
\hline Constant & 0 & 0 \\
Industrial load & 0.18 & 6 \\
Residential load & 0.92 & 4.04 \\
Commercial load & 1.51 & 3.4 \\
\hline
\end{tabular}

where $P_{i}$ and $Q_{i}$ are real and reactive power at bus $i, P_{o i}$ and $Q_{o i}$ are the active and reactive operating points at bus $i, V_{i}$ is the voltage at bus $i$, and $a$ and $r$ are active and reactive power exponents. Table 1 gives the load models exponent values [10, $11,13]$.

\section{Butterfly Particle Swarm Optimization (BF-PSO) Technique}

The butterfly-PSO (BF-PSO) algorithm is essentially based on the nectar probability and the sensitivity of the butterfly swarm [7]. In process for computing the optimal solution, the degree of node in every flight of butterfly is assumed as approximately equal to 1 because of assuming the maximum connectivity in each flight. The butterfly swarm based search process investigates the optimal location depending upon the sensitivity of butterfly toward the flower and the probability of nectar. The information about the optimal solution communicates directly or indirectly between all the butterflies by different means of communication intelligence (such as dancing, colors, chemicals, sounds, physical action, and natural processes) [8]. The butterfly leaning based particle swarm optimization algorithm has developed to ascertain the optimal solutions including the random parameters, acceleration coefficients, probability, sensitivity, lbest, and gbest. In the butterfly-PSO, lbest solutions are selected by the individual's best solution. After that, the gbest solution identified was based on the respective fitness. The locations (location) of the nectar (food) source represent the probable optimal solution for the problem and the amount of nectar (food) represents the corresponding fitness. The detail implementation of the butterfly-PSO (BF-PSO) technique is given below. The general ranges of the sensitivity and probability are considered from 0.0 to 1.0. The velocity limits can be set based on the limits of the problem variables. Hence, the function of inertia weight, sensitivity, and probability as a function of iterations can be given as $[7,8]$

$$
\begin{aligned}
& w_{k}=0.9-\left(\frac{(0.9-0.4)}{\mathrm{ITER}_{\text {max }}}\right) * \mathrm{ITER}_{k}, \\
& s_{k}=\exp -\frac{\left(\mathrm{ITER}_{\max }-\mathrm{ITER}_{k}\right)}{\mathrm{ITER}_{\max }}, \\
& p_{k}=\frac{\mathrm{FIT}_{\text {gbest }, k}}{\sum\left(\mathrm{FIT}_{\text {lbest }, k}\right)}
\end{aligned}
$$




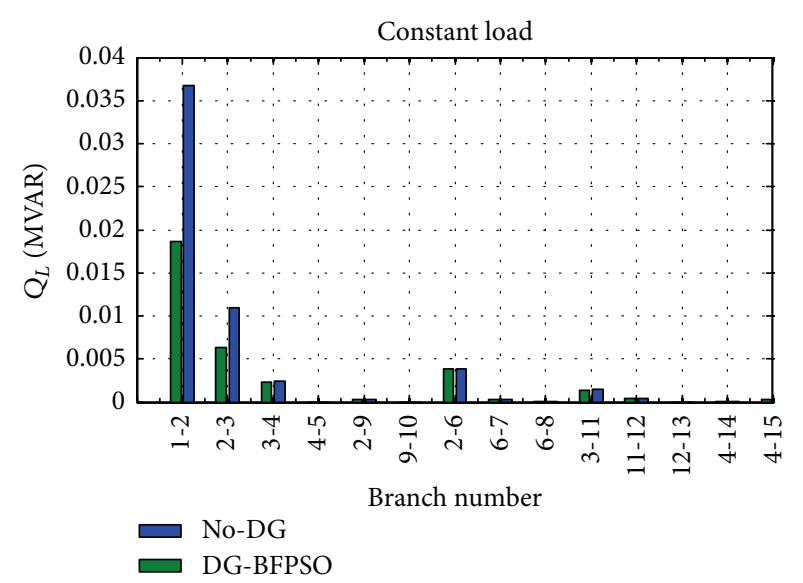

(a)

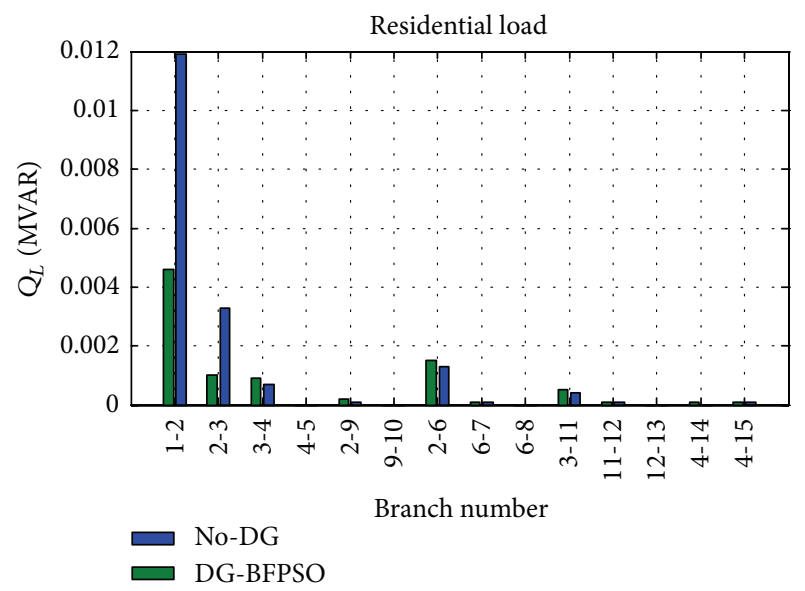

(c)

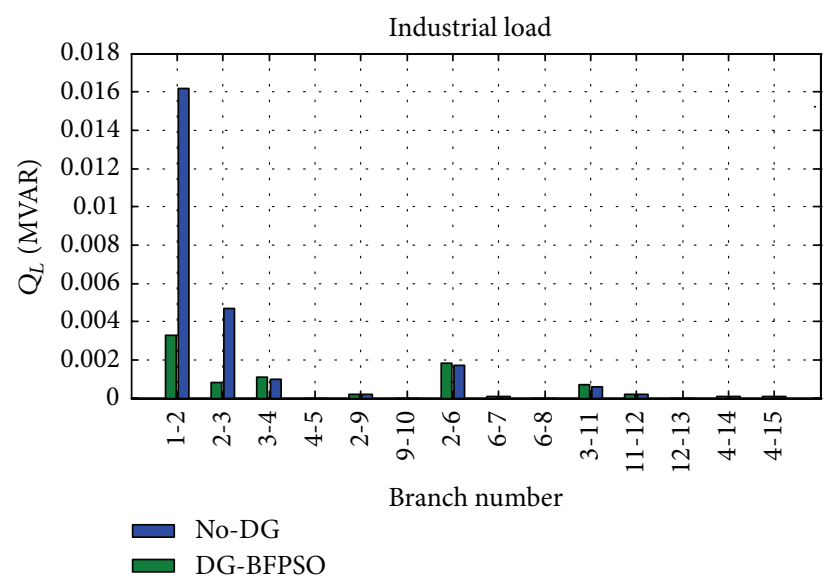

(b)

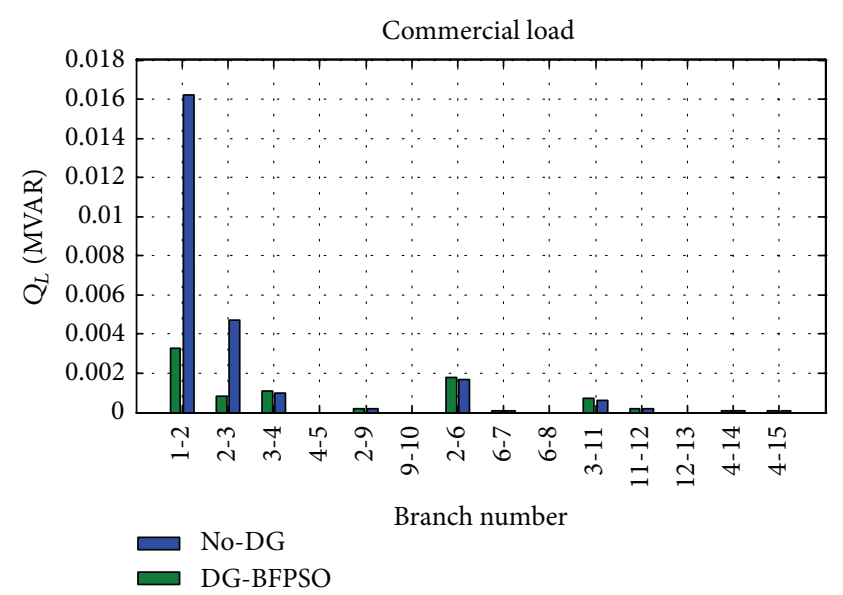

(d)

Figure 3: The reactive power loss of 15-bus radial system for (a) constant load, (b) industrial load, (c) residential load, and (d) commercial load.

where ITER $\mathrm{max}_{\max }$ is maximum number of iterations and $\mathrm{ITER}_{k}$ is $k$ th iteration count. And FIT $_{\text {lbest }, k}$ is fitness of local best solutions with $k$ th iteration and $\mathrm{FIT}_{\text {gbest }, k}$ is fitness of global best solutions with $k$ th iteration.

Then the equations of BF-PSO technique given below for the velocity and position updating are

$$
\begin{aligned}
v_{(k+1)}^{\prime}= & w * v_{k} \\
& +s_{k}\left(1-p_{k}\right) c_{1} r_{1}\left(\text { lbest }_{k}-\right.\text { currentpop) } \\
& +p_{k} c_{2} r_{2}\left(\text { gbest }_{k}-\right.\text { currentpop) } \\
x_{(k+1)}= & x_{k}+v_{k+1}^{\prime} .
\end{aligned}
$$

The detail algorithm to find the optimal sizing and location of DG using GA, PSO, and butterfly-PSO (BF-PSO) technique is given as follows:

(1) Read and input the systems data (bus data, line data, generation data, etc.).

(2) Run and execute the NR-power flow results for noDG case including load models.
(3) Initialize all the parameters of GA (population, selection rate, mutation rate, iterations, etc.), PSO $\left(c_{1}, c_{2}, w\right)$, and BF-PSO $\left(c_{1}, c_{2}, w_{k}, p_{k}\right.$, and $\left.s_{k}\right)$. The variables can be defined as

$$
x=\left[P_{\mathrm{dg} 1}, P_{\mathrm{dg} 2}, \ldots, P_{\mathrm{DGN}} ; L_{\mathrm{dg} 1}, L_{\mathrm{dg} 2}, \ldots, L_{\mathrm{DGN}}\right],
$$

where $N$ is number of population for GA, number of swarm for PSO, and the number of butterfly swarm for BF-PSO. The $P_{\mathrm{dg}}$ and $L_{\mathrm{dg}}$ are DG size and location, respectively.

(4) Update the variables within the algorithm using the different operators (selection, crossover, and mutation) for GA, equations (velocity and positions/locations) for PSO, and equations (velocity, locations, inertia weight, sensitivity, and probability) for BF-PSO.

(5) After that, assign the DG size and location in the system excluding the slack and PV buses.

(6) After that, call the NR-power flow and execute the results with DG condition including load models. 


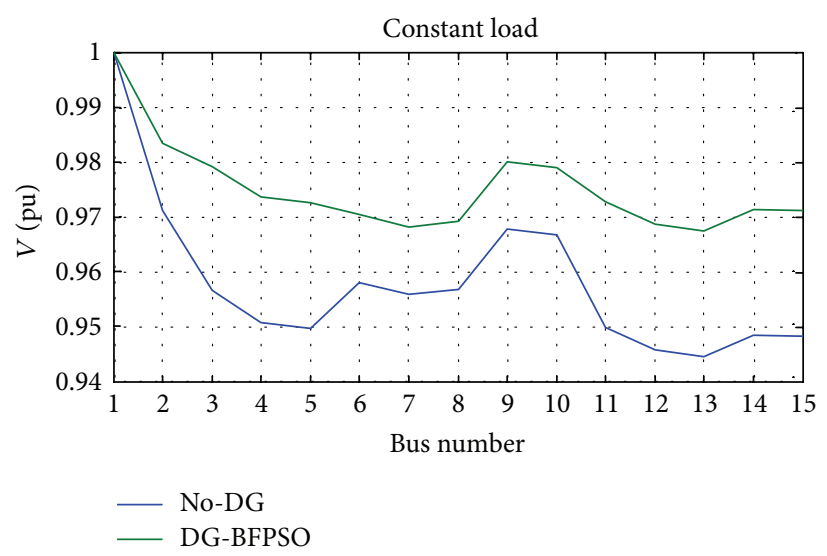

(a)

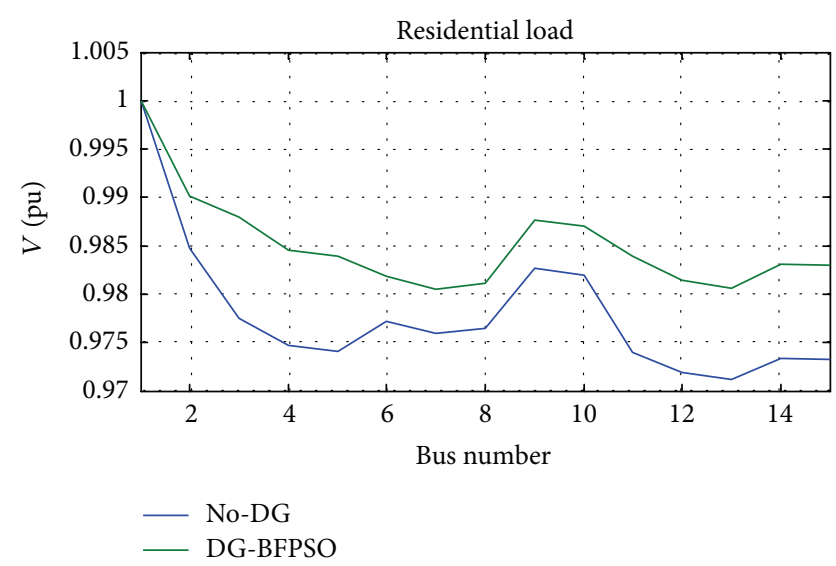

(c)

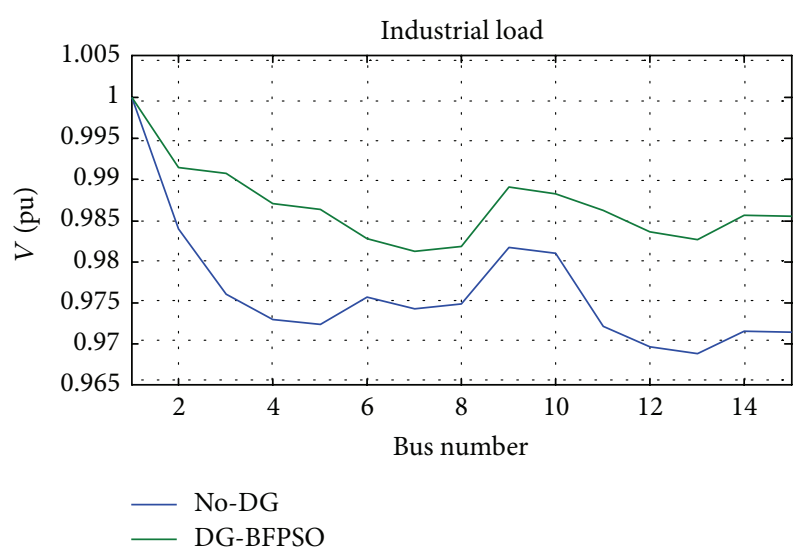

(b)

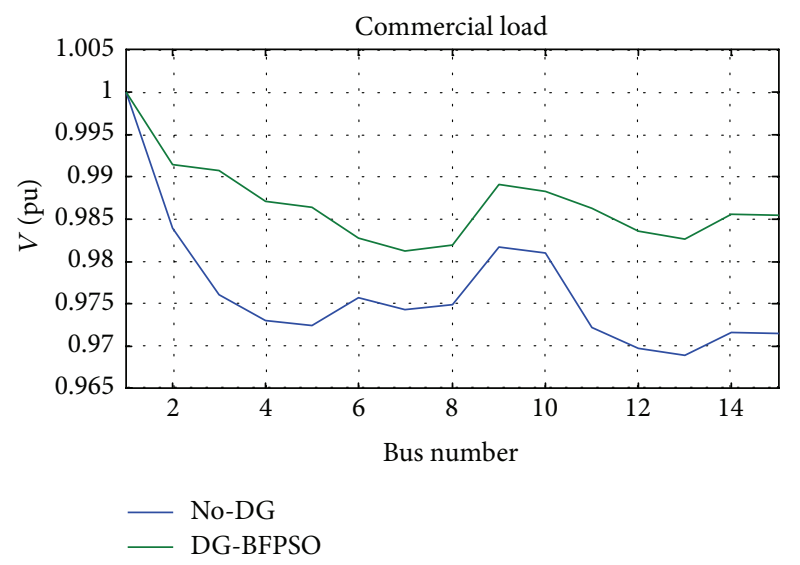

(d)

Figure 4: The voltage profile of 15-bus radial system for (a) constant load, (b) industrial load, (c) residential load, and (d) commercial load.

(7) Calculate the all indices value for the multiobjective function with each technique.

(8) Evaluate the fitness value for each technique of multiobjective function.

(9) Compare the variables from previous variables for each technique.

(10) Check for termination criteria; if otherwise, repeat algorithm from step (3) to step (9).

(11) Repeat this procedure up to maximum number of iterations.

(12) Record and save all the output data of the system.

The parameters such as population size for GA and also swarm size for PSO and BF-PSO are assumed 30 in all the test systems. The iterations for GA, PSO, and BF-PSO are assumed to be 50 , respectively, for all test systems.

\section{Results and Discussions}

This proposed algorithm has been tested on 15-bus radial system [9] and 30-bus mesh system [17, 18] with a base of 100 MVA. The range of DG size is 0.0 to maximum load (sum of all power demands) in the system. The DG is considered at a unity power factor. The loads are dependent on the voltage; that is, real and reactive load demand depends on the voltage magnitude of the particular bus. The range of DG size is 0.0 to maximum load (sum of all power demands) in the system. All the results for proposed methodology are carried out with MATLAB (2009a)/Matpowe4.1 tool with the system configuration Windows 8.1, AMD-E1-1500APU, $1.48 \mathrm{GHz}, 2.0 \mathrm{~GB}$ RAM.

4.1. The 15-Bus Radial System. The data of 15-bus radial system is given in [9]. The performance results of the 15bus radial system are shown in Figures 1-4. Figure 1 shows the results for the convergence of multiobjective function (FMO) with iterations for the constant, industrial, residential, and commercial loads. The convergence towards the optimal value of the function varies with an optimization technique as shown for GA, PSO, and BF-PSO. The comparative analysis indicates that the convergence of BF-PSO technique is better and faster than GA and PSO. Hence overall system performance is computed by BF-PSO technique.

The impacts of load models on the active and reactive power losses of 15-bus radial system are shown in Figures 2 and 3, respectively. The BF-PSO reveals that the active and reactive power loss of system with constant, industrial, residential, and commercial loads are varied in the same 


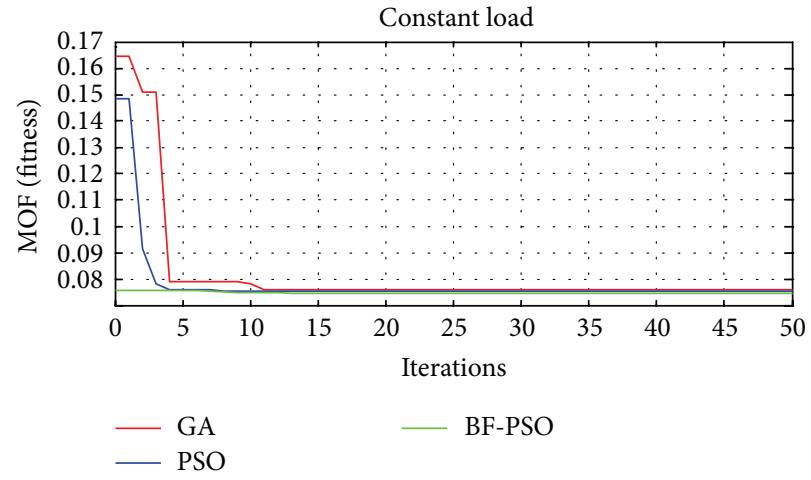

(a)

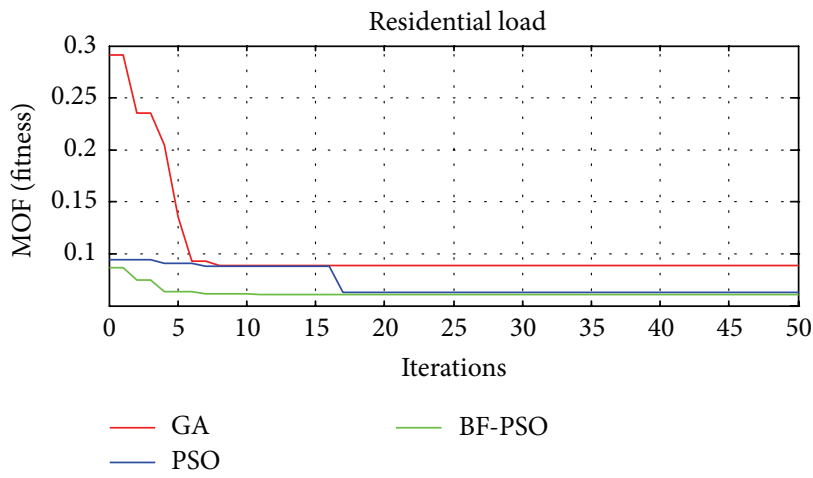

(c)

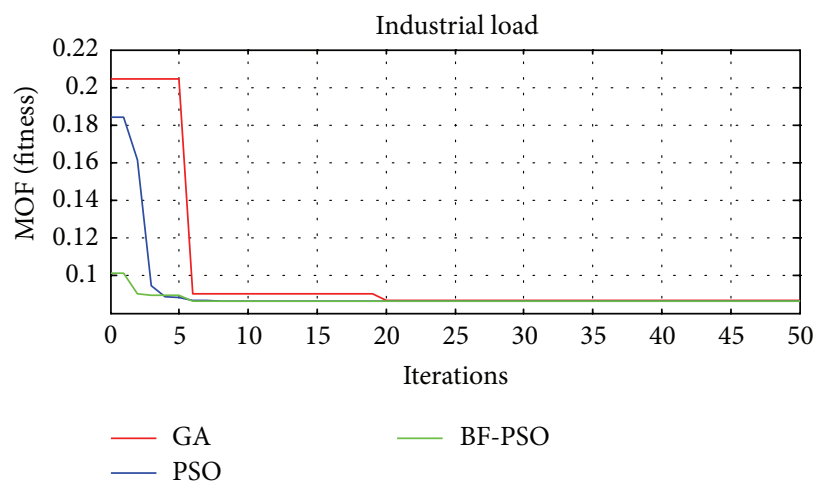

(b)

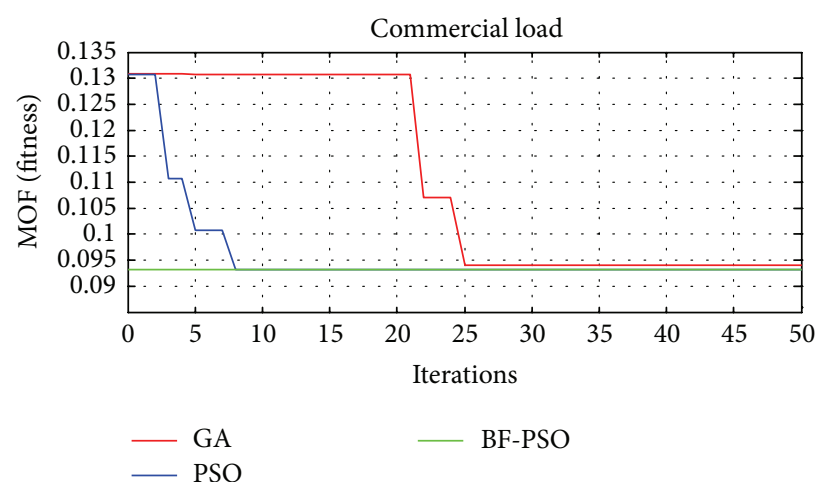

(d)

FIGURE 5: The convergence of multiobjective function (FMO) with iterations of 30-bus mesh system for (a) constant load, (b) industrial load, (c) residential load, and (d) commercial load.

proportion as size and the location of DG vary. The active power loss of system with DG using BF-PSO technique is less as compared to without- or no-DG case. The impacts of load models on sizing and siting as well as on the active power losses are different with DG. The reactive power losses without and with DG using BF-PSO technique for load models are given in Figure 3. The result shows the effect of the load models on the reactive power loss with DG condition.

The impact of different load models on the voltage profile using BF-PSO is shown in Figure 4. The voltage profiles of the system are distinguished for the different type of load models. The improvement in the voltage profile with DGBFPSO is more efficient for all load models. Table 2 gives the values of the system indices using different methods with DG condition. These values are the optimal solution values of different technique for load models. Value of the multiobjective function (FMO), size of DG, (PDG) and optimal bus location of DG are given in Table 3. Minimum value of the fitness function (FMO) is obtained using BF-PSO method for all load models, hence all system results evaluated for BF-PSO method. The value of FMO is 0.4335, PDG is 1.0355 and optimal bus location is 3 using BF-PSO for the constant load. The value of FMO is 0.4346, PDG is 0.9703 and optimal bus location is 3 using PSO for the constant load. The value of FMO is 0.4375 , PDG is 1.1596 and optimal bus location is 3 using GA for the constant load. Similarly the impacts of industrial, residential and commercial load models on
TABLE 2: Objective indices of 15-bus radial system with different load models using GA, PSO, and BF-PSO.

\begin{tabular}{lcccc}
\hline Load type & PLI & QLI & VDI & Technique \\
\hline \multirow{3}{*}{ Constant load } & 0.6123 & 0.5931 & 0.0324 & BF-PSO \\
& 0.6133 & 0.594 & 0.0338 & PSO \\
& 0.6188 & 0.6001 & 0.0302 & GA \\
\hline \multirow{3}{*}{ Industrial load } & 0.3782 & 0.3404 & 0.0187 & BF-PSO \\
& 0.402 & 0.3662 & 0.02 & PSO \\
& 0.5006 & 0.4483 & 0.022 & GA \\
\hline \multirow{3}{*}{ Residential load } & 0.5453 & 0.5093 & 0.0195 & BF-PSO \\
& 0.5637 & 0.5303 & 0.0212 & PSO \\
& 0.644 & 0.6003 & 0.0229 & GA \\
\hline \multirow{4}{*}{ Commercial load } & 0.6603 & 0.6285 & 0.0198 & BF-PSO \\
& 0.6715 & 0.6379 & 0.0188 & PSO \\
& 0.7387 & 0.7034 & 0.0227 & GA \\
\hline
\end{tabular}

the multi-objective function (FMO), size of DG, (PDG) and optimal bus location of DG can be analyzed.

4.2. The 30-Bus Mesh System. The all data information about the 30-bus mesh system data have given in [17]. The proposed algorithm applied to minimize the multi-objective function for the 30-bus mesh system in this section. The results of the 30-bus mesh system are shown in Figures 5-8 and Tables 4-6. 


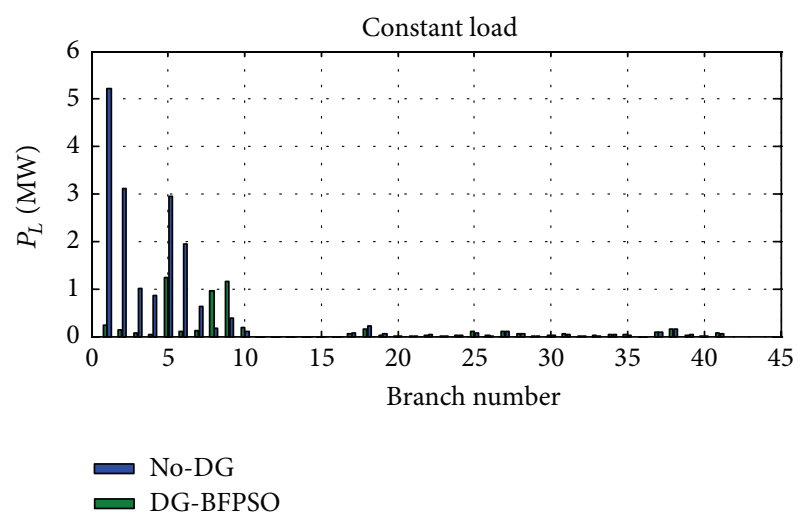

(a)

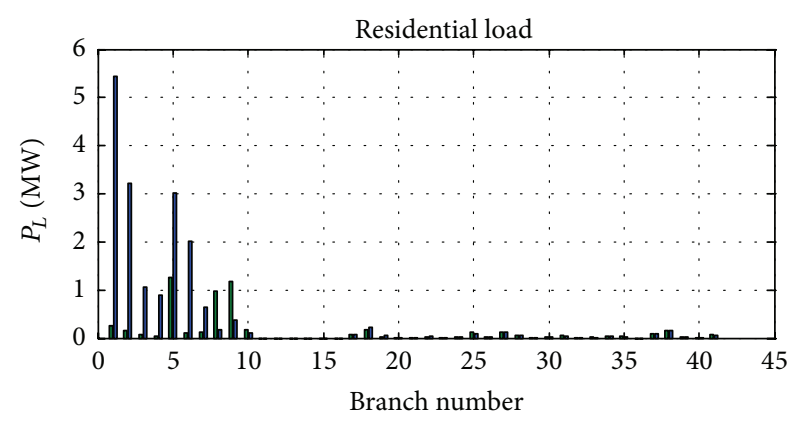

No-DG

DG-BFPSO

(c)

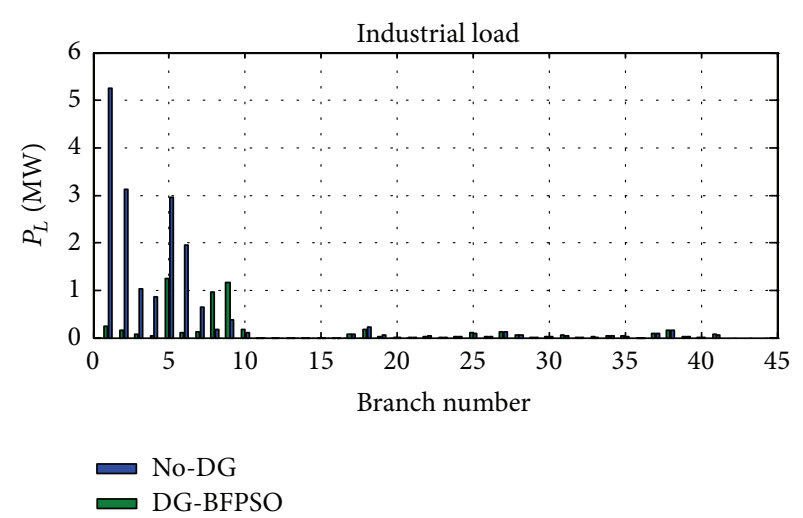

(b)

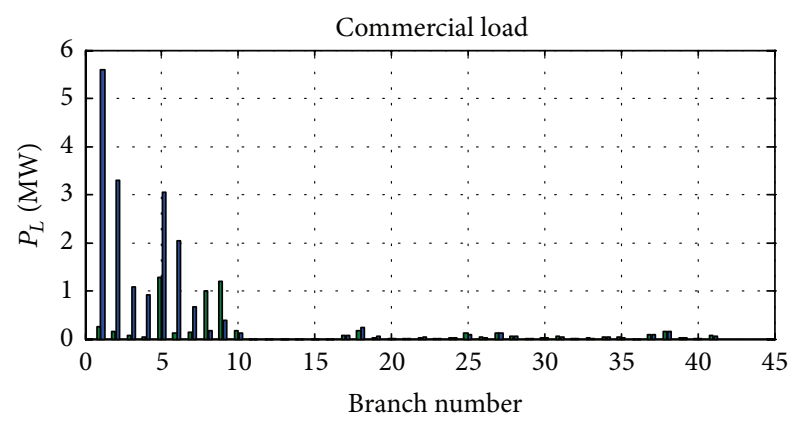

No-DG
DG-BFPSO

FIGURE 6: Active power loss of 30-bus mesh system for (a) constant load, (b) industrial load, (c) residential load, and (d) commercial load.

TABLE 3: Multiobjective function and DG size at optimal bus location with different load models for 15-bus radial system using GA, PSO, and BF-PSO.

\begin{tabular}{lcccc}
\hline Load Type & Fitness (FMO) & PDG & Bus & Technique \\
\hline \multirow{3}{*}{ Constant load } & 0.4335 & 1.0355 & 3 & BF-PSO \\
& 0.4346 & 0.9703 & 3 & PSO \\
& 0.4375 & 1.1596 & 3 & GA \\
\hline \multirow{3}{*}{ Industrial load } & 0.2609 & 0.8549 & 3 & BF-PSO \\
& 0.2785 & 0.7232 & 4 & PSO \\
& 0.3439 & 0.5862 & 15 & GA \\
\hline \multirow{3}{*}{ Residential load } & 0.3786 & 0.672 & 3 & BF-PSO \\
& 0.3926 & 0.5697 & 4 & PSO \\
& 0.4467 & 0.4502 & 15 & GA \\
\hline \multirow{3}{*}{ Commercial load } & 0.4602 & 0.5505 & 3 & BF-PSO \\
& 0.4673 & 0.644 & 3 & PSO \\
& 0.5151 & 0.363 & 15 & GA \\
\hline
\end{tabular}

The result for convergence of multi-objective function (FMO) with iterations for the constant, industrial, residential and commercial loads are shown in Figure 5. The convergence towards the optimal value of the function varies with an optimization technique for 30-bus mesh system as shown for GA, PSO and BF-PSO. The comparative analysis indicates that the convergence of BF-PSO technique is better and faster than GA and PSO. Hence overall 30-bus mesh system performance is computed only for BF-PSO technique. The BF-PSO results for active power loss of system with constant, industrial, residential and commercial loads are shown in Figure 6. The result presents that the active power loss of system with DG using BF-PSO technique is less as compared to that without DG condition. The impacts of load models on size and location as well as on the active power losses of 30-bus mesh system are different with DG cases. The reactive power losses without and with DG using BF-PSO technique for 30-bus mesh system with load models are given in Figure 7. The result shows the effect of the load models on the reactive power loss of 30-bus mesh system with DG condition.

The voltage profiles of the system are dissimilar for the particular load models of the system. The change in voltage profiles of the system occurs due to variations in the size and location of DG. The impact of different load models on the voltage profile of 30-bus mesh system using BF-PSO is shown in Figure 8. The improvement in the voltage profile with DGBFPSO is more efficient for all load models. The values of the system indices for 30-bus mesh system using different methods with DG condition are given in Table 4 . These values are the optimal solution values of different technique for load models. The value of multiobjective function (FMO), size 


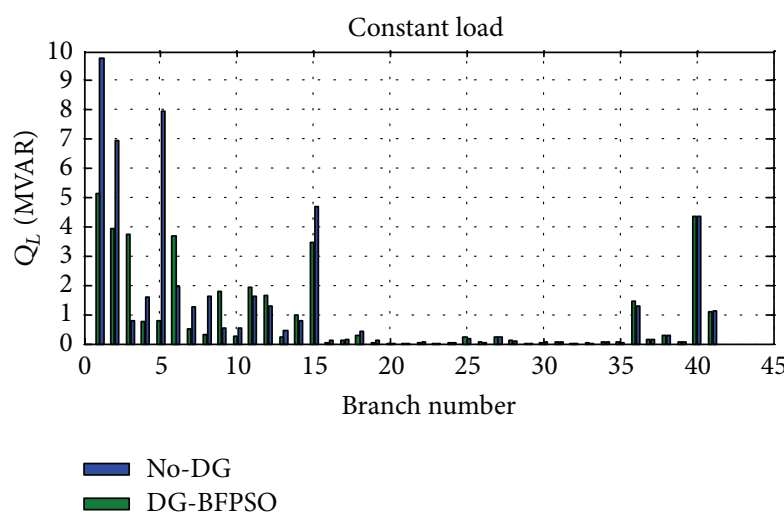

(a)

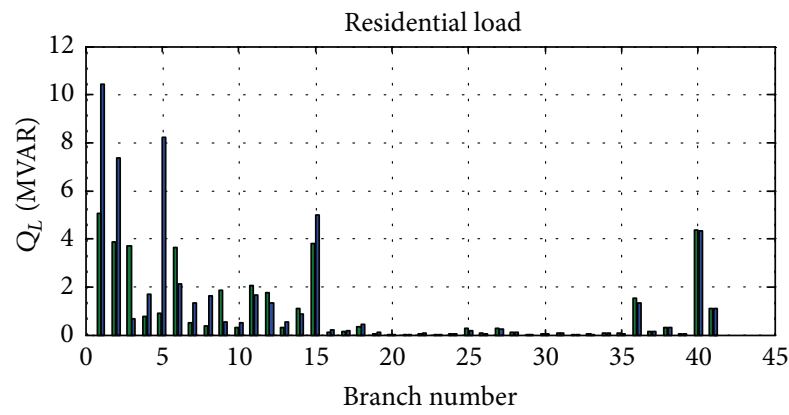

No-DG

ए DG-BFPSO

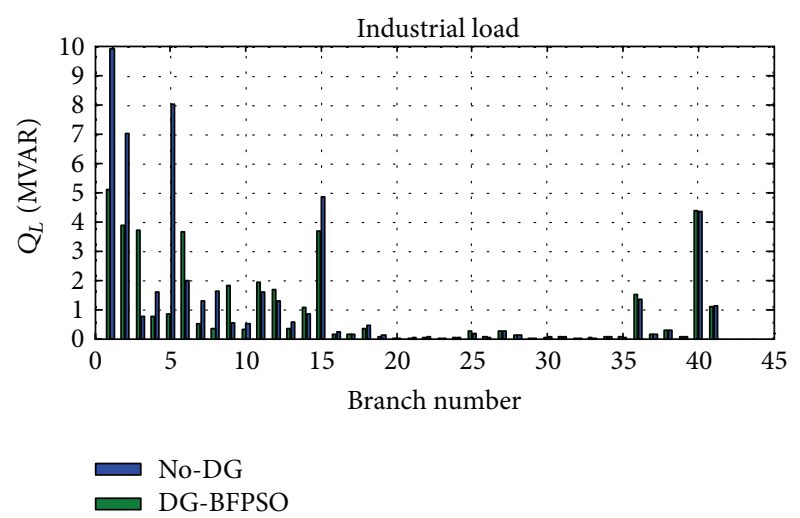

(b)

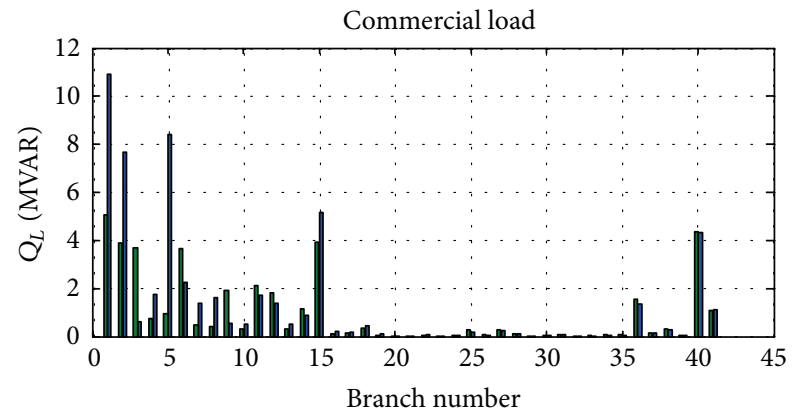

No-DG
DG-BFPSO

(c)

(d)

FIGURE 7: The reactive power loss of 30-bus mesh system for (a) constant load, (b) industrial load, (c) residential load, and (d) commercial load.

TABLE 4: Objective indices of 30-bus mesh system with different load models using GA, PSO, and BF-PSO.

\begin{tabular}{lcccc}
\hline Load type & PLI & QLI & VDI & Technique \\
\hline \multirow{3}{*}{ Constant load } & 0.3073 & -0.2643 & -0.0048 & BF-PSO \\
& 0.3071 & -0.2634 & -0.0046 & PSO \\
& 0.3185 & -0.2528 & -0.006 & GA \\
\hline \multirow{4}{*}{ Industrial load } & 0.3111 & -0.2296 & 0.0004 & BF-PSO \\
& 0.3155 & -0.2266 & -0.0002 & PSO \\
& 0.3197 & -0.2215 & -0.0004 & GA \\
\hline \multirow{3}{*}{ Residential load } & 0.3078 & -0.2032 & -0.001 & BF-PSO \\
& 0.3085 & -0.2034 & -0.0012 & PSO \\
& 0.317 & -0.1799 & 0.0001 & GA \\
\hline \multirow{4}{*}{ Commercial load } & 0.3059 & -0.1791 & -0.0016 & BF-PSO \\
& 0.3068 & -0.179 & -0.0018 & PSO \\
& 0.3061 & -0.1765 & -0.0012 & GA \\
\hline
\end{tabular}

of DG (PDG), and optimal bus location of DG are given in Table 5. The minimum value of fitness function (FMO) is obtained by using BF-PSO technique for different load models; hence all system results are evaluated for BF-PSO method. The value of FMO is $0.0708, \mathrm{PDG}$ is 202.9922, and optimal bus location is 6 using BF-PSO for the constant load. The value of FMO is 0.0710, PDG is 199.2922, and optimal
TABLE 5: Multiobjective function and DG size at optimal bus location with different load models for 30-bus mesh system using GA, PSO, and BF-PSO.

\begin{tabular}{lcccc}
\hline Load type & $\begin{array}{c}\text { Fitness function } \\
\text { (FMO) }\end{array}$ & PDG & Bus & Technique \\
\hline \multirow{3}{*}{ Constant load } & 0.0708 & 202.9922 & 6 & BF-PSO \\
& 0.0710 & 199.2922 & 6 & PSO \\
& 0.0784 & 226.1614 & 6 & GA \\
\hline \multirow{3}{*}{ Industrial load } & 0.0827 & 203.2873 & 7 & BF-PSO \\
& 0.0853 & 216.8522 & 7 & PSO \\
& 0.0884 & 223.5097 & 6 & GA \\
\hline \multirow{3}{*}{ Residential load } & 0.0874 & 206.3894 & 7 & BF-PSO \\
& 0.0876 & 210.8828 & 7 & PSO \\
& 0.0977 & 179.2814 & 7 & GA \\
\hline \multirow{3}{*}{ Commercial load } & 0.0924 & 210.0633 & 6 & BF-PSO \\
& 0.0925 & 215.0907 & 6 & PSO \\
& 0.0932 & 201.9343 & 6 & GA \\
\hline
\end{tabular}

bus location is 6 using PSO for the constant load. The value of FMO is 0.0784 , PDG is 226.1614 , and optimal bus location is 6 using GA for the constant load. Similarly, the impacts of industrial, residential, and commercial load models on 


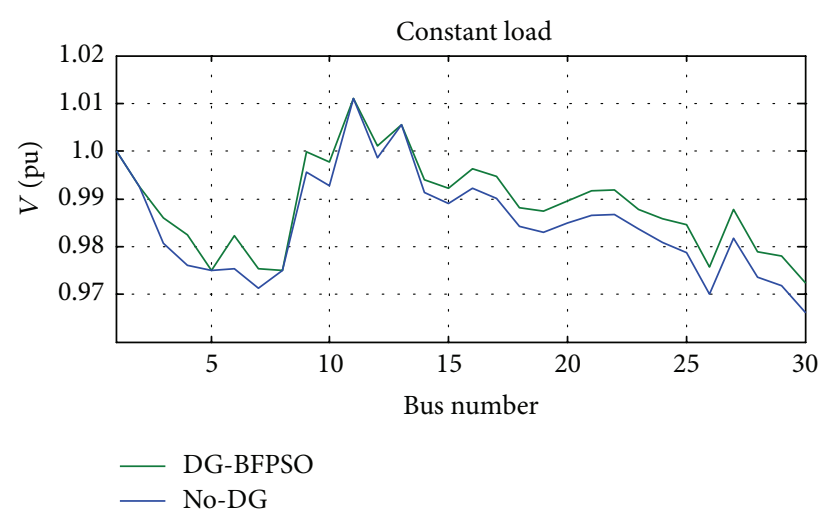

(a)

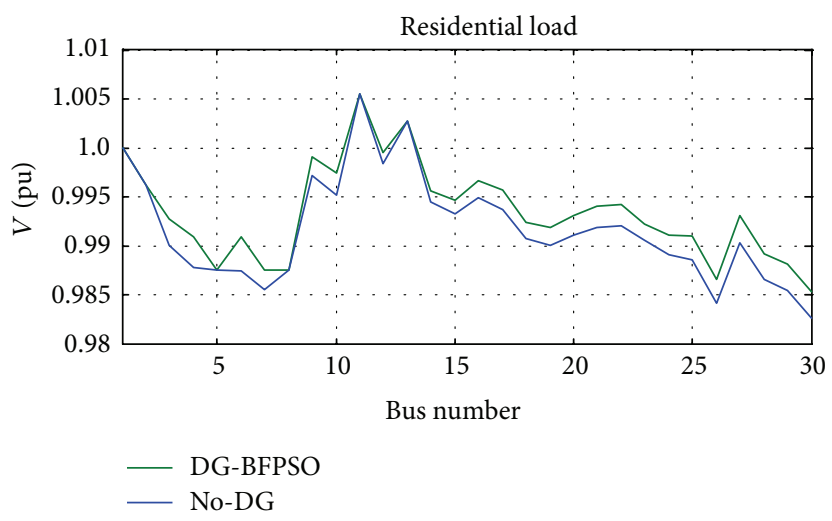

(c)

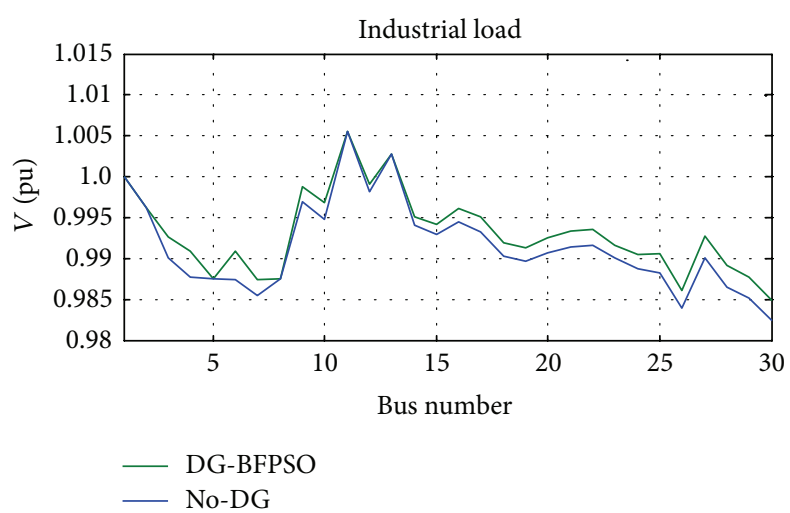

(b)

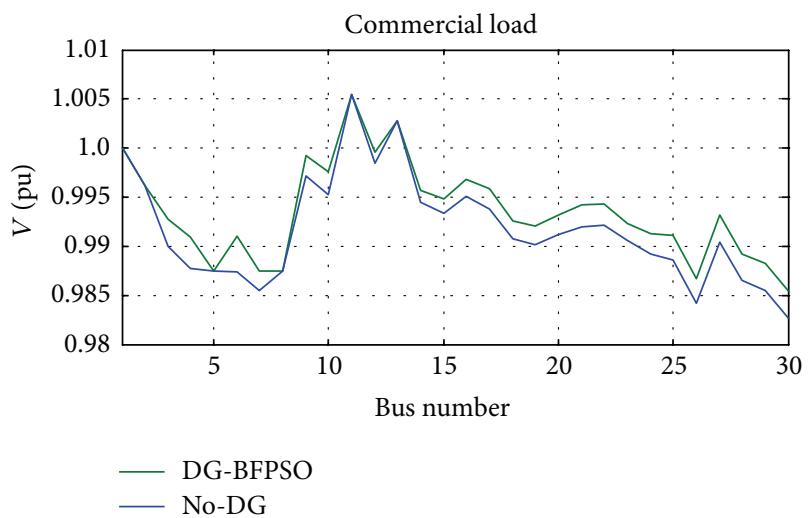

(d)

Figure 8: The voltage profile of 30-bus mesh system for (a) constant load, (b) industrial load, (c) residential load, and (d) commercial load.

TABLE 6: The comparative analysis of 30-bus radial system.

\begin{tabular}{|c|c|c|c|c|}
\hline \multirow[b]{2}{*}{ Cases } & \multicolumn{4}{|c|}{ Parameter } \\
\hline & $\begin{array}{l}\text { Active power } \\
\text { loss (MW) }\end{array}$ & $\begin{array}{c}\text { Active power loss } \\
\text { reduction }(\%)\end{array}$ & $\begin{array}{c}\text { Reactive power loss } \\
\text { (MVAr) }\end{array}$ & $\begin{array}{c}\text { Reactive power loss } \\
\text { reduction }(\%)\end{array}$ \\
\hline Without-DG (base case) & 17.557 & - & 67.69 & - \\
\hline \multicolumn{5}{|l|}{ With-DG } \\
\hline Existing (7.5\% DG penetration) & $7.0973[17]$ & $59.57 \%$ & NA & NA \\
\hline Proposed (DG-BFPSO) & 5.396 & $69.27 \%$ & 26.32 & $61.11 \%$ \\
\hline
\end{tabular}

the multiobjective function (FMO), size of DG (PDG), and optimal bus location of DG can be analyzed.

The comparative analysis of the proposed and the existing methodology is given in Table 6 for the 30-bus mesh system. This analysis shows that the reduction in active power loss with existing methodology is $59.57 \%$. The reduction in active and reactive power losses with the proposed methodology is $69.27 \%$ and $61.11 \%$, respectively, for 30 -bus mesh system. This result analysis accomplishes the idea that the more power loss reduction is achieved by proposed methodology as compared to existing methodology.

\section{Conclusions}

The proposed methodology is implemented on the 15-bus radial and 30-bus mesh system and the comparative analysis for 30-bus mesh system with proposed and the existing methodology is given in Section 4. It shows that reduction in active power loss with existing methodology is up to $59.57 \%$, whereas the reduction in active and reactive power losses with the proposed methodology is up to $69.27 \%$ and $61.11 \%$, respectively, for 30-bus mesh system. Hence the more power loss reduction is obtained by proposed methodology than the existing one. This result analysis demonstrates that the BF-PSO technique based algorithm is an efficient algorithm on the basis of hybridization of butterfly and the particle swarm techniques. It is observed that the hybridization of two allegiant techniques provides the unique combo to evaluate the system performance. In this work also the presented results are compared between with- and without-DG cases using GA, PSO, and BF-PSO technique. The effect of different types of load in the system is assumed, while tackling the 
optimal sizing and siting of DG problems in the system. It is clearly shown in the results that the performance of the system such as reduction in losses and increase in voltages has improved. Also, the size and location of DG vary with different load models for GA, PSO, and BF-PSO technique.

\section{Conflict of Interests}

The authors declare that there is no conflict of interests regarding the publication of this paper.

\section{Acknowledgments}

The authors wish to acknowledge the MANIT, Bhopal, and MHRD for financial support. Furthermore, the authors want to extend acknowledgment to those who have supported them directly or indirectly.

\section{References}

[1] J. H. Holland, Adaptation in Natural and Artificial Systems, The University of Michigan Press, Ann Arbor, Mich, USA, 1975.

[2] D. E. Goldberg, Genetic Algorithms in Search, Optimization and Machine Learning, Addison-Wesley, 1st edition, 1989.

[3] R. L. Haupt and S. E. Haupt, Practical Genetic Algorithms, John Wiley \& Sons, Hoboken, NJ, USA, 2nd edition, 2004.

[4] E. Bonabeau, M. Dorigo, and G. Theraulaz, Swarm Intelligence: From Natural to Artificial Systems, Oxford University Press, Oxford, UK, 1999.

[5] J. Kennedy and R. Eberhart, "Particle swarm optimization," in Proceedings of the IEEE International Conference on Neural Networks, vol. 4, pp. 1942-1948, Perth, Australia, December 1995.

[6] R. C. Eberhart and J. Kennedy, "A new optimizer using particle swarm theory," in Proceedings of the 6th International Symposium on Micro Machine and Human Science (MHS '95), pp. 3943, IEEE Service Center, Nagoya, Japan, October 1995.

[7] A. K. Bohre, G. Agnihotri, and M. Dubey, "Hybrid butterfly based particle swarm optimization for optimization problems," in Proceedings of the 1st International Conference on Networks and Soft Computing (ICNSC '14), pp. 172-177, Guntur, India, August 2014.

[8] A. K. Bohre, G. Agnihotri, M. Dubey, and J. S. Bhadoriya, "A novel method to find optimal solution based on modified butterfly particle swarm optimization," International Journal of Soft Computing, Mathematics and Control, vol. 3, no. 4, pp. 1-14, 2014.

[9] D. Das, D. P. Kothari, and A. Kalam, "Simple and efficient method for load flow solution of radial distribution networks," International Journal of Electrical Power and Energy Systems, vol. 17, no. 5, pp. 335-346, 1995.

[10] D. Singh, D. Singh, and K. S. Verma, "Multiobjective optimization for DG planning with load models," IEEE Transactions on Power Systems, vol. 24, no. 1, pp. 427-436, 2009.

[11] A. M. El-Zonkoly, "Optimal placement of multi-distributed generation units including different load models using particle swarm optimization," Swarm and Evolutionary Computation, vol. 1, no. 1, pp. 50-59, 2011.

[12] R. S. Rao, K. Ravindra, K. Satish, and S. V. L. Narasimham, "Power loss minimization in distribution system using network reconfiguration in the presence of distributed generation," IEEE Transactions on Power Systems, vol. 28, no. 1, pp. 317-325, 2013.

[13] L. F. Ochoa, A. Padilha-Feltrin, and G. P. Harrison, "Evaluating distributed generation impacts with a multiobjective index," IEEE Transactions on Power Delivery, vol. 21, no. 3, pp. 14521458, 2006.

[14] D. Thukaram, H. M. Wijekoon Banda, and J. Jerome, "A robust three phase power flow algorithm for radial distribution systems," Electric Power Systems Research, vol. 50, no. 3, pp. 227236, 1999.

[15] R. D. Zimmerman and C. E. Murillo-Sanchez, "Matpower4.1," December 2011, http://www.pserc.cornell.edu//matpower/.

[16] H. Sadat, Power System Analyses, TMH Publication, 2002.

[17] F. Ugranli and E. Karatepe, "Convergence of rule-of-thumb sizing and allocating rules of distributed generation in meshed power networks," Renewable and Sustainable Energy Reviews, vol. 16, no. 1, pp. 582-590, 2012.

[18] A. K. Bohre, G. Agnihotri, and M. Dubey, "The OPF and butterfly-PSO (BF-PSO) technique based optimal location and sizing of distributed generation in mesh system," Electrical and Electronics Engineering: An International Journal, vol. 4, no. 2, pp. 127-141, 2015. 

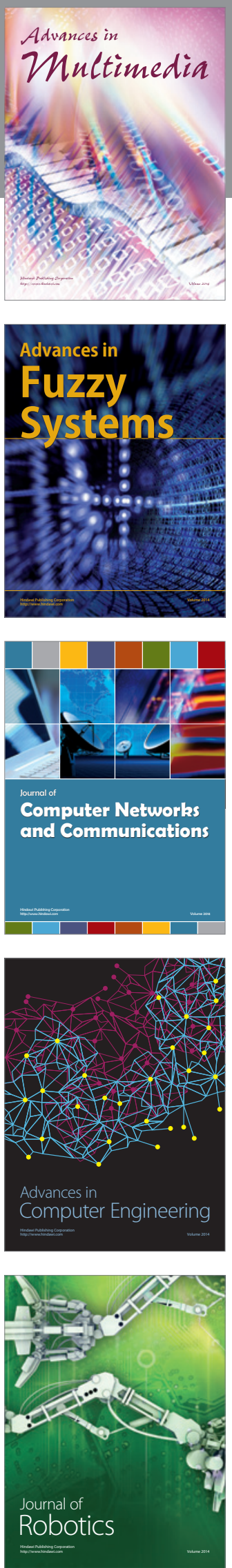

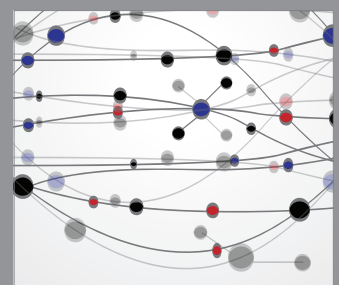

The Scientific World Journal
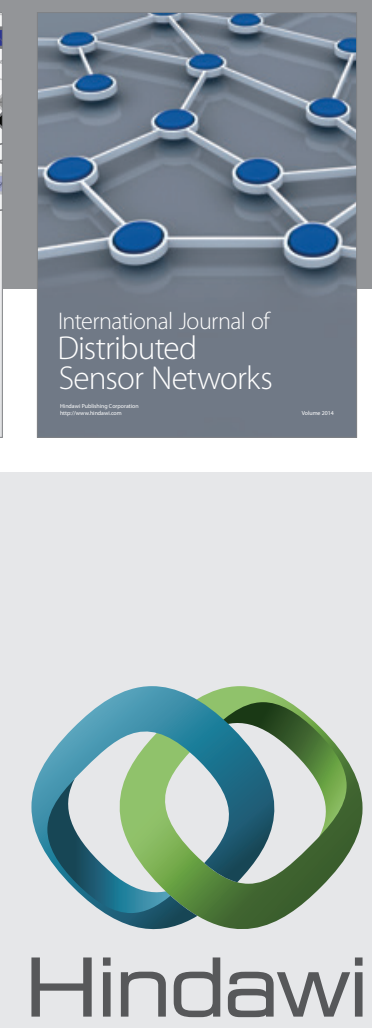

Submit your manuscripts at

http://www.hindawi.com
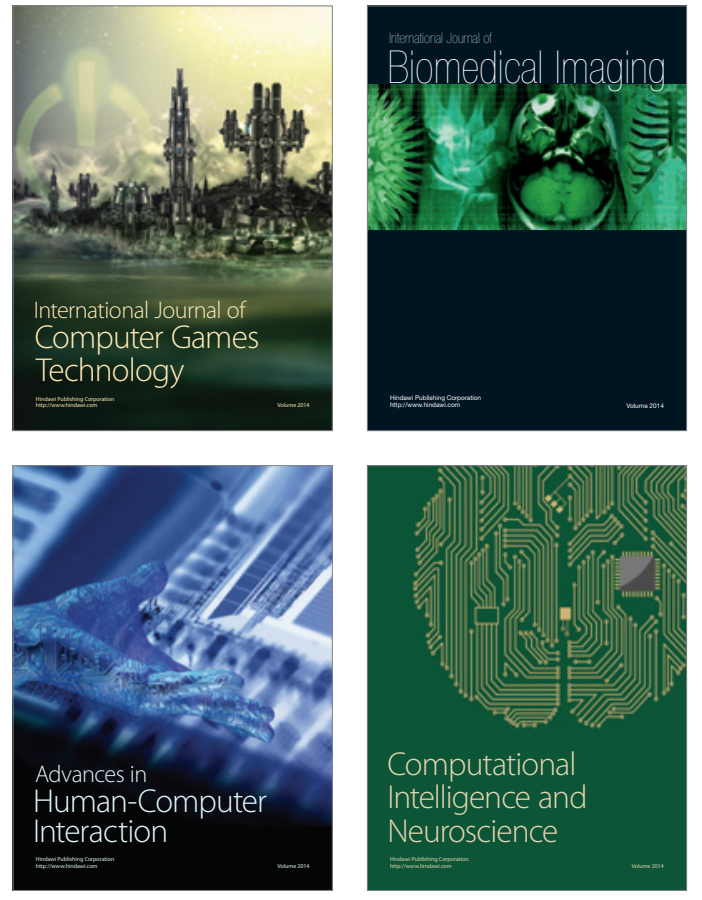
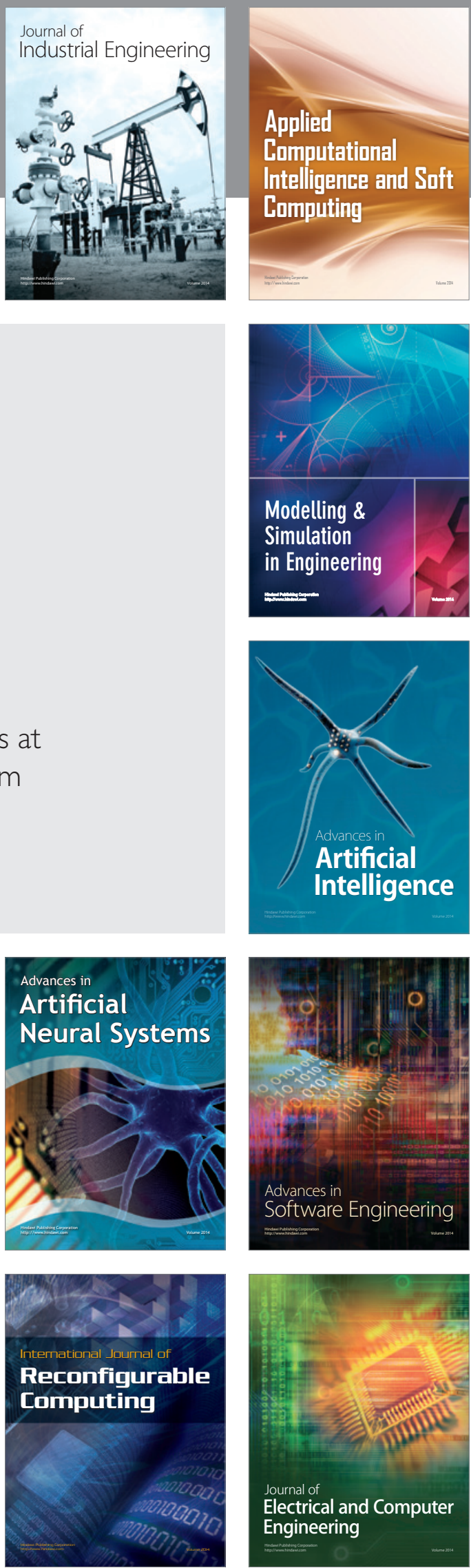